\title{
Optimized generated power of a solar PV system using an intelligent tracking technique
}

\author{
Afshin Balal ${ }^{1}$, Mostafa Abedi ${ }^{2}$, Farzad Shahabi ${ }^{3}$ \\ ${ }^{1}$ Department of Electrical and Computer Engineering, Texas Tech University, USA \\ ${ }^{2}$ Department of Electrical and Computer Engineering, Northeastern University, USA \\ ${ }^{3}$ Department of Electrical and Computer Engineering, University of South Florida, USA
}

\begin{tabular}{l}
\hline \hline Article Info \\
\hline Article history: \\
Received Jul 21, 2021 \\
Revised Sep 24, 2021 \\
Accepted Oct 1, 2021 \\
\hline
\end{tabular}

\section{Keywords:}

Distributed maximum power Fuzzy/Bee hybrid method Partial shading condition Power production PV system

\begin{abstract}
Partial shading condition (PSC) is common and complicated in all types of PV power plants. Therefore, the power production of a solar system would be affected by the mismatch phenomena produced by PSC. Furthermore, when the array is partially shaded, the $\mathrm{P}-\mathrm{V}$ characteristics become more complex, which causes multiple peaks of the P-V curve. So, the simple maximum power point tracking (MPPT) methods such as perturb and observe (P\&O) will fail. To address the above issue, this paper proposes a combination of two different approaches, implementing distributed MPPT (DMPPT) and optimized fuzzy/bee algorithm (OFBA). DMPPT can be utilized to maximize solar energy by allowing each module, or group of modules, to be managed independently. Also, due to the output power oscillations around the operating point in the $\mathrm{P} \& \mathrm{O}$ method, an OFBA is employed, which allowing for the decrease of output power oscillations without the usage of temperature and light sensors. The result shows that utilizing of DMPPT control approach in conjunction with the OFBA boosts the output generated power.
\end{abstract}

This is an open access article under the CC BY-SA license.

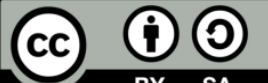

\section{Corresponding Author:}

\author{
Afshin Balal \\ Department of Electrical and Computer Engineering \\ Texas Tech University \\ 910 Boston Ave, Lubbock, TX, USA \\ Email: Afshin.balal@ttu.edu
}

\section{INTRODUCTION}

Because of the scarcity of fossil fuels and the effects of climate change, renewable energy is becoming increasingly attractive. Solar energy is a pollution-free system with lower maintenance costs distributed all over the earth [1]. The PV source's main disadvantage is not working during cloudy days or nighttime [2]. Also, the PV system does not work properly with having partially shaded modules, and PSC generates several MPPs in the P-V curve [3], [4]. To achieve high operational points, the output voltage of the PV system must be continuously adjusted to match changing atmospheric conditions, ensuring that power generated is constantly at its maximum value [5], [6]. Maximum power production can be reached in a photovoltaic system by modifying the operating point of the arrays for specific conditions. The main disadvantages of solar PV systems are that their power output is mainly dependent on climatic factors such as sunshine and climate temperature, both of which have nonlinear P-I and V-I characteristics [7]. As a result, PV systems have low efficiency, and it is not possible to effectively use solar energy in varied conditions [8], [9]. Figure 1 shows the different possible MPPs of the system by changing the sun radiation, ambient temperature, and PSCs.

Several types of researche have been done to increase the output solar power by using intelligent algorithms. The authors of [10] examine the Futoshiki puzzle model under PSCs, which increases output power by changing the place of panels without altering the modules' electrical connections. In [11], a global MPPT 
(GMPPT) algorithm is investigated by utilizing an artificial bee colony (ABC) to generate the best duty cycles from each substring. The suggested method allows for a considerable decrease in the number of voltage and current sensors. The authors of [12] proposed an MPPT based on artificial bee colonies. The designed algorithm produces a simple and resilient MPPT scheme that demonstrates excellent performance. In [13], the author examines a buck/boost converter for a DMPPT system that can get suitable output under different conditions.

The aim of this paper is to increase power production by using the DMPPT alongside with intelligent tracking technique. DMPPT topology, in which each PV module is connected to the energy system via independent MPPT converters, maximizes the capacity of the photovoltaic module and also increases efficiency. Furthermore, there are different basic and optimized MPPT algorithms in PV systems to attain maximum power, such as $\mathrm{P} \& \mathrm{O}$, incremental conductance (IC), and so on [14]-[18]. In this paper, $\mathrm{P} \& \mathrm{O}$ and fuzzy logic control (FLC) methods are being studied. However, because of the output power oscillations around the operating point of the P\&O method and the lowest speed of the FLC method, an optimized fuzzy/bee algorithm is used, which decreases the output power oscillation and also increases the speed of finding MPPs.

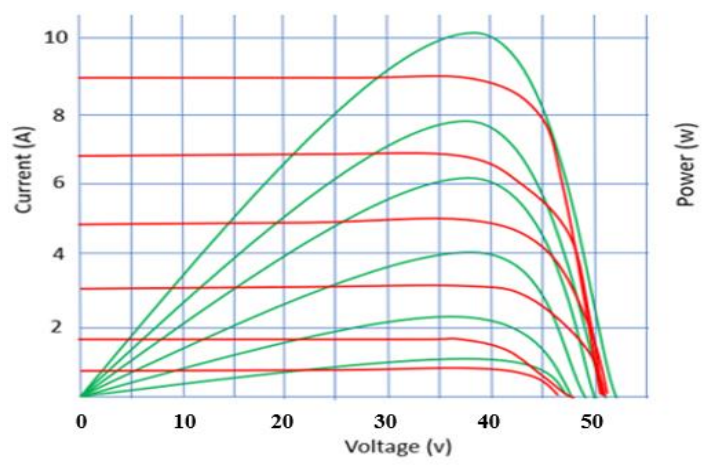

Figure 1. Different maximum power points

\section{SOLAR PV DESIGN}

Because PV power production is influenced by different sun radiation and weathers, therefore output power fluctuates [19]. In order to construct an appropriate solar system, cell temperature and solar irradiation, as well as information on the system's composition, such as rated power, number of panels, and so on, are necessary [20].

\subsection{Solar cell circuit}

Figure 2 depicts a solar cell's one-diode equivalent circuit. Solar panels, of course, are made up of a succession of solar cells arranged in a parallel pattern.

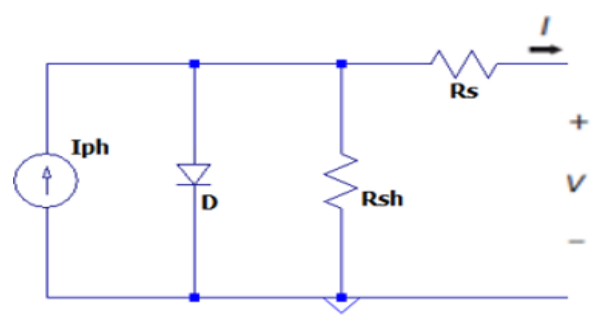

Figure 2. An equivalent model of a one diode cell

In Figure 2, the I-V characteristic of the cell is stated using (1). By using (1), the output current of the PV system will be defined.

$$
I=N_{P} I_{S H}-N_{P} I_{S}\left[\left(\frac{q\left(\frac{V}{N_{S}}+\frac{I R_{S}}{N_{P}}\right)}{K T A}\right)-1\right]-\frac{\left(\frac{N_{P} V}{N_{S}}+I R_{S}\right)}{R_{S H}}
$$


Where $R_{S}$ and $R_{S H}$ are the series and parallel resistance of the solar cell, V and I are the voltage and the output current, $I_{S}$ is the diode's saturation current, $N_{P}$ and $N_{S}$ are the numbers of parallel and series cells, $\mathrm{T}$ is the cell temperature in terms of Kelvin, and $\mathrm{A}$ is the ideal coefficient for diode, $\mathrm{K}$ is Boltzmann's constant which is equal to $K=1.23 \times 10^{23}$ and $q=1.6 \times 10^{-19}$ is the charge of an electron in units of coulomb (C), and $I_{S H}$ is the photovoltaic current [21].

\subsection{Characteristic of the solar module}

The characteristics of a PV panel that is used are indicated in Table 1. Each panel in the PV system has 96 cells connected in series.

Table 1. Features of the PV module under STC condition

\begin{tabular}{llll}
\hline Cells per module & 96 & Tilt angle & $25^{\circ} \mathrm{C}$ \\
\hline Operation temperature & $-40^{\circ} \mathrm{C}$ to $+85^{\circ} \mathrm{C}$ & Latitude & $33.60^{\circ} \mathrm{C}$ \\
modules & 144 & Longitude & $101.89^{\circ} \mathrm{C}$ \\
Efficiency & $18.71 \%$ & Azimuth & $180^{\circ} \mathrm{C}$ south \\
Rated DC power & $305.22 \mathrm{~W}$ & Frame & Class 1 black anodized aluminum \\
Voltage V(OC) & $64.20 \mathrm{~V}$ & Weight & $20.6 \mathrm{~kg}$ \\
Current I (SC) & $5.96 \mathrm{~A}$ & Size & 41.2 in $* 61.3$ in \\
Maximum MPP current & $5.58 \mathrm{~A}$ & Type of module & Monocrystalline \\
Maximum MPP voltage & $54.68 \mathrm{~V}$ & Mounting system & Fixed rack \\
\hline
\end{tabular}

The system reported in this study has a rated DC power per module of 305.22 watts, a $\mathrm{V}_{\mathrm{OC}}$ of 64.2 volts, and an ISC of 5.96 amperes. Then, in Table 1, all of the required parameters are listed, including Rated power, $\mathrm{I}_{\mathrm{SC}}, \mathrm{V}_{\mathrm{OC}}, \mathrm{V}_{\mathrm{MPP}}$, and $\mathrm{I}_{\mathrm{MPP}}$. In Table 2, the PV cell's parameters which are significantly temperaturedependent, are listed below for $0^{\circ} \mathrm{C}, 25^{\circ} \mathrm{C}$, and $50^{\circ} \mathrm{C}$. Then, the operating points of the $\mathrm{I}-\mathrm{V}$ characteristic curves could be calculated.

Table 2. Cell's parameters in different temperature

\begin{tabular}{llll}
\hline & $0^{\circ} \mathrm{C}$ & $25^{\circ} \mathrm{C}$ & $50^{\circ} \mathrm{C}$ \\
\hline DC power $\mathrm{P}_{\mathrm{DC}}$ & $331.30 \mathrm{~W}$ & $305.22 \mathrm{~W}$ & $279.01 \mathrm{~W}$ \\
Light-generated current $\mathrm{I}_{\mathrm{L}}$ & $5.95 \mathrm{~A}$ & $5.96 \mathrm{~A}$ & $5.98 \mathrm{~A}$ \\
Short-circuit current $\mathrm{I}_{\mathrm{SC}}$ & $5.94 \mathrm{~V}$ & $5.96 \mathrm{~A}$ & $5.97 \mathrm{~A}$ \\
Open-circuit voltage $\mathrm{V}_{\mathrm{OC}}$ & $68.49 \mathrm{~V}$ & $64.20 \mathrm{~V}$ & $59.85 \mathrm{~V}$ \\
Voltage at maximum power point $\mathrm{V}_{\mathrm{MP}}$ & $59.24 \mathrm{~V}$ & $54.68 \mathrm{~V}$ & $50.15 \mathrm{~V}$ \\
Current at maximum power point $\mathrm{I}_{\mathrm{MP}}$ & $5.59 \mathrm{~A}$ & $5.58 \mathrm{~A}$ & $5.56 \mathrm{~A}$ \\
Efficiency & $20.31 \%$ & $18.71 \%$ & $17.11 \%$ \\
\hline
\end{tabular}

Also, according to the Figure 3, the P-V and I-V curves for the different temperature has been plotted in MATLAB. Based on Figure 3, by increasing the temperature, the generated power decreases. Therefore, $0^{\circ}$ $\mathrm{C}$ has the highest power, production and the temperature of $50^{\circ} \mathrm{C}$ has the lower power production.

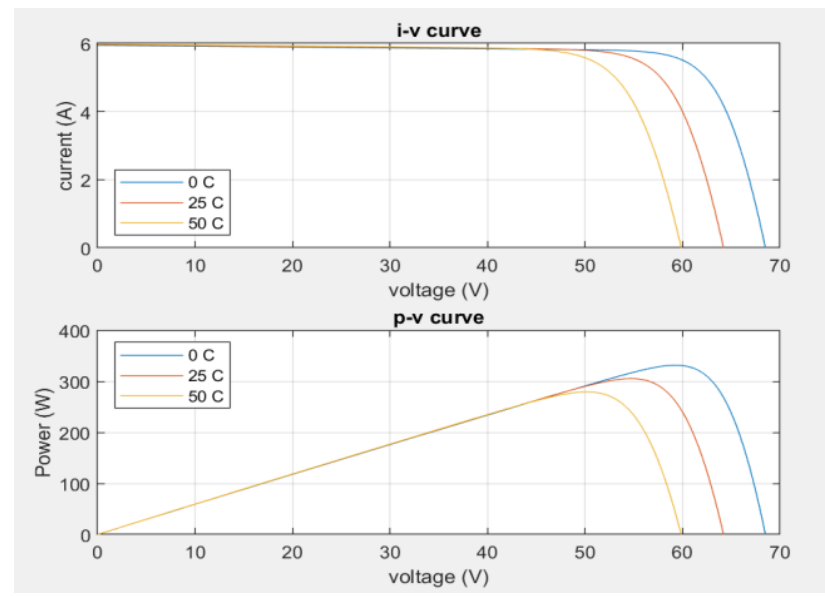

Figure 3. I-V and $\mathrm{P}-\mathrm{V}$ curve of $0^{\circ} \mathrm{C}, 25^{\circ} \mathrm{C}$, and $50^{\circ} \mathrm{C}$ 


\section{CONTROLLER DESIGN}

The optimum converter must be chosen to transfer the highest amount of power from the solar cell to the output load. Then, a buck-boost dc-dc (BBDC) converter may match the required voltage in the subsystem load to change the output voltage of the solar cells [22], [23]. As a result, it appears that a BBDC converter is a good option. The controller part of the proposed system consists of a BBDC converter that uses the MPPT system by implementing P\&O, FLC, and FBA methods to achieve maximum power.

\subsection{Buck-boost de to dc converter}

In order to utilize a BBDC converter, the capacitor and inductor values are determined in (2) and (3) [24], [25]. Equation 2 defines the inductor value of the BBDC, and (3) also defines the capacitor value of the converter.

$$
\begin{aligned}
& L=\frac{V_{O} T_{S}(1-D)^{2}}{2 I_{O B}} \\
& C=\frac{V_{O} D T_{S}}{R \Delta V}
\end{aligned}
$$

In (2), $\mathrm{I}_{\mathrm{OB}}$ is the output boundary current, and in Equation (3), $\Delta \mathrm{V}$ is the output voltage ripple. Figure 4 shows a schematic of a BBDC converter. According to Figure 4, a BBDC converter consists of a MOSFET connected to the DC sources, an inductor, a diode, and a capacitor to reduce the ripple of the output.

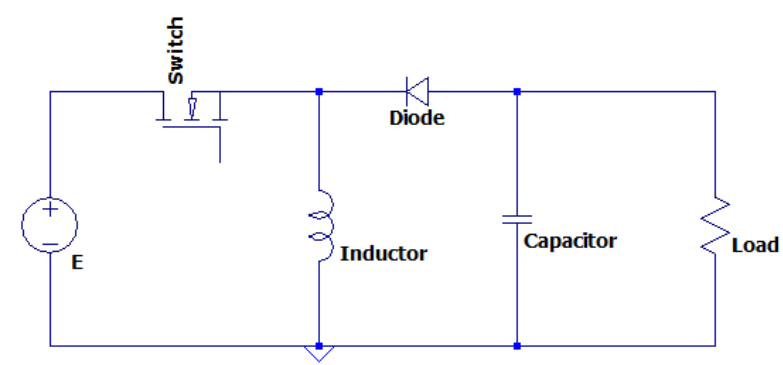

Figure 4. Simulation of a BBDC converter

\subsection{Maximum power point tracking (MPPT)}

The I-V characteristic of nonlinear solar arrays is affected by radiation and temperature changes, as mentioned earlier. An MPPT system must be created to tackle this problem. As shown in Figure 5, the BBDC converter is used as a power processor to match the load to the solar array and absorb as much energy as possible [26], [27]. According to Figure 5, an MPPT controller consists of PV arrays, a BBDC converter, and voltage and current measurement sensors.

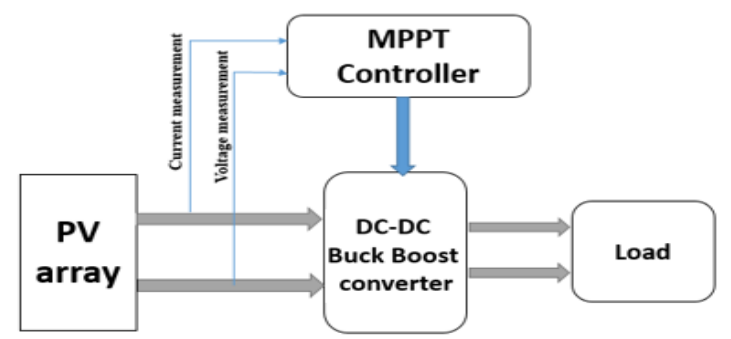

Figure 5. Block diagram of the MPPT system

\subsection{Perturb and observe method $(\mathbf{P \& O})$}

As stated in the introduction, a range of strategies and approaches can be employed to carry out the concept of tracking the MPP. The P\&O approach is the most well-known of them [28], [29]. P\&O algorithm can be seen in Figure 6. 


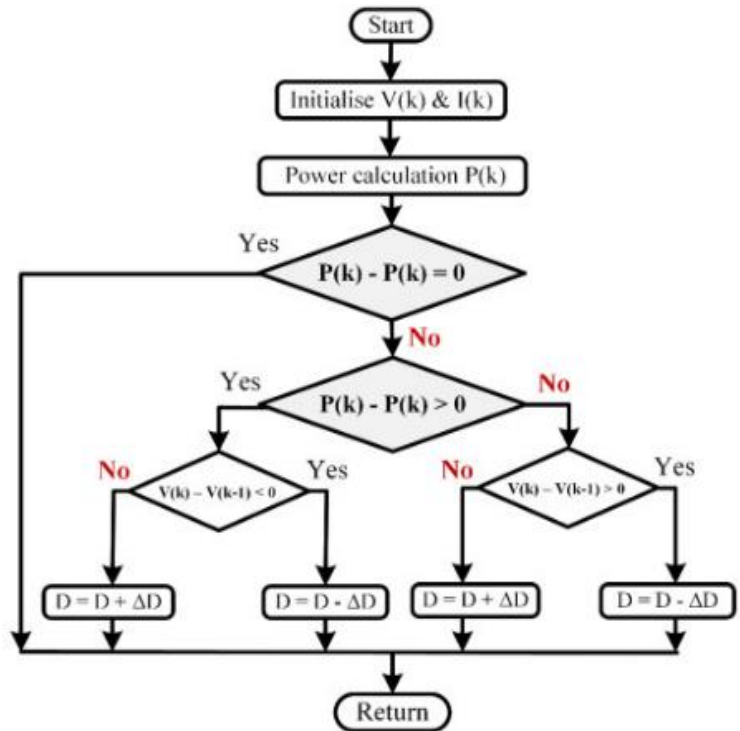

(a)

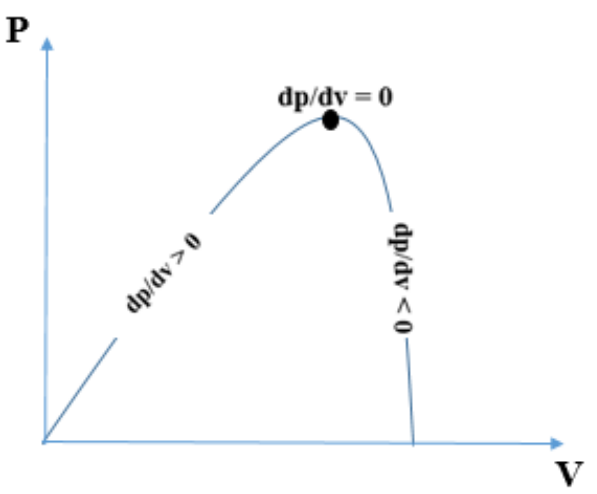

(b)

Figure 6. P \& O method, (a) P\&O algorithm, and (b) P-V curve

According to Figure 6(a), a slight perturbation $\Delta D$ is used to cause the PV module's power to vary. On a regular basis, the PV output power is measured and compared to the previous power. If the output power increases, the procedure is repeated; otherwise, the perturbation is reversed. As shown in Figure 6(b), when utilizing the $\mathrm{P} \& \mathrm{O}$ method, the ratio of $\frac{d p}{d v}$ equals zero at the highest power point, is positive prior to this point, and then becomes negative after that. If $\frac{d p}{d v}$ is positive, it should keep going in the same direction until it hits zero; If it's negative, it should keep going in the other direction until it gets the intended result. When choosing MPPT systems, there are two main things to consider: simplicity and accuracy which are the main features of $\mathrm{P} \& O$ method [30], [31]. However, this method is slow, and it generates output power oscillation around the operational points under a variety of conditions, such as cloudy days.

\subsection{Fuzzy logic control (FLC)}

For uniform irradiation circumstances, controller modeling is easier. However, when it comes to designing for the PSC, the problem becomes important since the system will be unnecessarily complicated. The entire tracking process must be enhanced in order to increase efficiency, particularly when tracking in rapidly changing weather conditions. The PV system must be mathematically modeled before the controller can be designed. As a result, an intelligent technique was developed that does not require the system to be mathematically modeled. Trackers that rely on FLC are considered to be smart because the controller achieves high efficiency regardless of whether the information is accurate or not [32]-[34]. This FLC has two key advantages over other techniques: 1) FLC is able to work without having a perfect model, and 2) the FLC design is solely in the hands of humans [35]. The fuzzy rules, which are one of three main components, are designed using human expertise. Fuzzification, fuzzy rules, and defuzzification are the three stages of the FLC approach in general [36]-[38].

The inputs for the PV system are turned into linguistic parameters during fuzzification. The main purpose of if-then rules is to provide linguistic variables parameters by applying human understanding [39]. Defuzzification is a fuzzification opposite procedure that uses mathematical relations to extract linguistic parameters. The FLC output is converted from a linguistic variable to a numerical variable during the defuzzification phase, and this is fed into the converter as an analog signal [40]. The triangle membership function for both the system's input and output in this system, the singleton fuzzifier, the Mamdani inference engine, and the average center defuzzifier were employed. The different input levels are defined in Table 3 so that they should fully cover the variation range. As Table 3 indicates, there are 25 fuzzy rules-based.

Therefore, it fully covers five variables, including negative big (NB), negative small (NS), ZE (zero), PS (positive small), PS (positive small), PB (positive big). A thorough understanding of the behavior of the photovoltaic system is required to develop a fuzzy controller and select fuzzy rules. The maximum power point, according to Figure 6 , has an important attribute of $\frac{d p}{d v}=0$. The points having the property of $\frac{d p}{d v}>0$ have the 
voltage less than the voltage of the optimal point (MPP), and the points with the property of $\frac{d p}{d v}<0$ have more than the voltage of the optimal point. The above-mentioned behavioral trait will be exploited in this paper to determine the maximum power point by FLC [41]. Figure 7 indicates the use of this technique for PV. For this purpose, the following variables are generated:

$$
\begin{aligned}
& E(t)=\frac{P_{P V}(t)-P_{P V}(t-1)}{V_{P V}(t)-V_{P V}(t-1)} \\
& C E(t)=E(t)-E(t-1)
\end{aligned}
$$

In (4) and (5), P (t) and V (t) are the instantaneous power and voltage values, respectively. In this paper, the fuzzy controller input $E(t)$ and $C E(t)$, and the output is the pulse signal. Variable $E(t)$ represents the variation of power to voltage variations, and $C E(t)$ represents the variation rate of $E(t)$; these variables will be available to the fuzzy inference machine after fuzzification so that the fuzzy variable $\operatorname{CD}(\mathrm{t})$ can be determined, which is equal to:

$$
\mathrm{CD}(\mathrm{t})=\mathrm{D}(\mathrm{t})-\mathrm{D}(\mathrm{T}-1)
$$

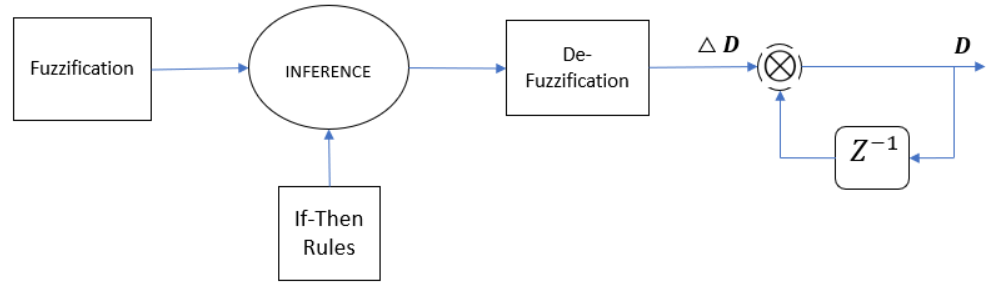

Table 3. Fuzzy rule base

\begin{tabular}{cccccc}
\hline & NB & NS & Z & PS & PB \\
\hline NB & NB & NB & NB & Z & Z \\
NS & NS & NS & NS & Z & Z \\
Z & NS & Z & Z & Z & PS \\
PS & Z & Z & PS & PS & PS \\
PB & Z & Z & PB & PB & PB \\
\hline
\end{tabular}

Figure 7. Block diagram of FLC technique

\subsection{Artificial bee colony (ABC)}

$\mathrm{ABC}$ is a different way, used in MPPT application and inspired by honey bees' attempts for food and their proper cooperation. The analogy of honey bees is implemented in the application of this approach. These honey bees reside in colonies and divide themselves into groups to find food. Similarly, the optimal MPP is found by assigning each tracking operation to its own process. Honey bees can be divided into three groups: employed, onlookers, and scouts. Information about the food which is gathered by the employed honey bee kicks off the procedure. In a systematic mathematical approach, the information is passed on to the observer honey bees [42], [43]. At the same time, the scouts are looking for substitute meals. No need to mention that each nectar source's location offers a solution to the problem. The fitness of the related solution is proportional to the nectar amount of the nectar source. As shown in (7), indicates the bees that match to the i'th honey source look for a new honey source. In addition, the corresponding hired bees become scout bees, and the scout bees use the (8) to find additional probable solutions.

$$
\begin{aligned}
& V_{i k}=X_{i k}+\varphi_{i k}\left(X_{i k}-X_{j k}\right) \\
& X_{i k}=X_{k}^{\text {min }}+\operatorname{random}(0,1)\left(X_{k}^{\text {max }}-X_{k}^{\text {min }}\right)
\end{aligned}
$$

Where $X_{k}^{\min }$ and $X_{k}^{\max }$ are the lower and upper bounds, respectively, $\mathrm{i}=1,2,3,4,5, \ldots, \mathrm{N}, \mathrm{d}=1,2$, $3,4,5, \ldots, \mathrm{D}, \varphi_{i k}$ is a random number between $(-1,1)$. Finally, each onlooker bee chooses a honey source based on probability, which is computed according to (9).

$$
P_{i}=\frac{f_{i}}{\sum_{n=1}^{N} f_{n}}
$$

Where $f_{i}$ is the adaptive value of $X_{i k}$ as a potential solution. The ultimate goal is to collect information on the most plentiful food supply. The algorithm performs better when the number of hired bees in the group is more abundant. This food-finding method is well-suited to PV systems, which use the right activation approach to find the optimum point [44]. A location of MPP is tracked much better using this technique. The efficiency of the ABC technique is almost 98 percent [45]. 


\section{PROPOSED METHOD}

The novelty of the proposed method is that this article proposes a combination of two separate approaches, including DMPPT and the intelligent Fuzzy/Bee tracking method.

\subsection{Distributed maximum power point tracking (DMPPT)}

The DMPPT approach is used to reduce the output power drop produced by PV module operation conditions that aren't compatible [46]. In this scenario, as shown in Figure 8, a parallel rather than a series connection of modules is investigated. Grid-connected inverters have a different input voltage. To generate the desired output power, a series of PV modules are commonly connected in series to provide an input voltage within the inverter's operating range, and identical strings are then connected in parallel. A system made up of a sequence of parallel strings will be evaluated for these reasons. Microinverters can be used to convert DC voltage from each module to AC power in a PV system with a smaller number of modules. The PV system described in this study is made up of eight strings, each with 18 modules. In this instance, string inverters are the optimum type of inverter. The grid-connected solar power system with distributed maximum power point tracking utilizing string inverters is shown in Figure 9. According to Figure 9, in the proposed DMPPT, three arrays are in series together, which are paralleled with other groups of three arrays to be controlled independently.

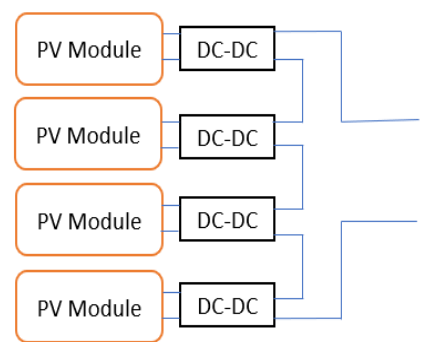

(a)

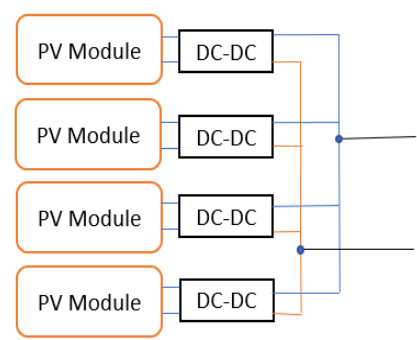

(b)

Figure 8. Distributed PV system, (a) distributed series modules (b) distributed parallel modules

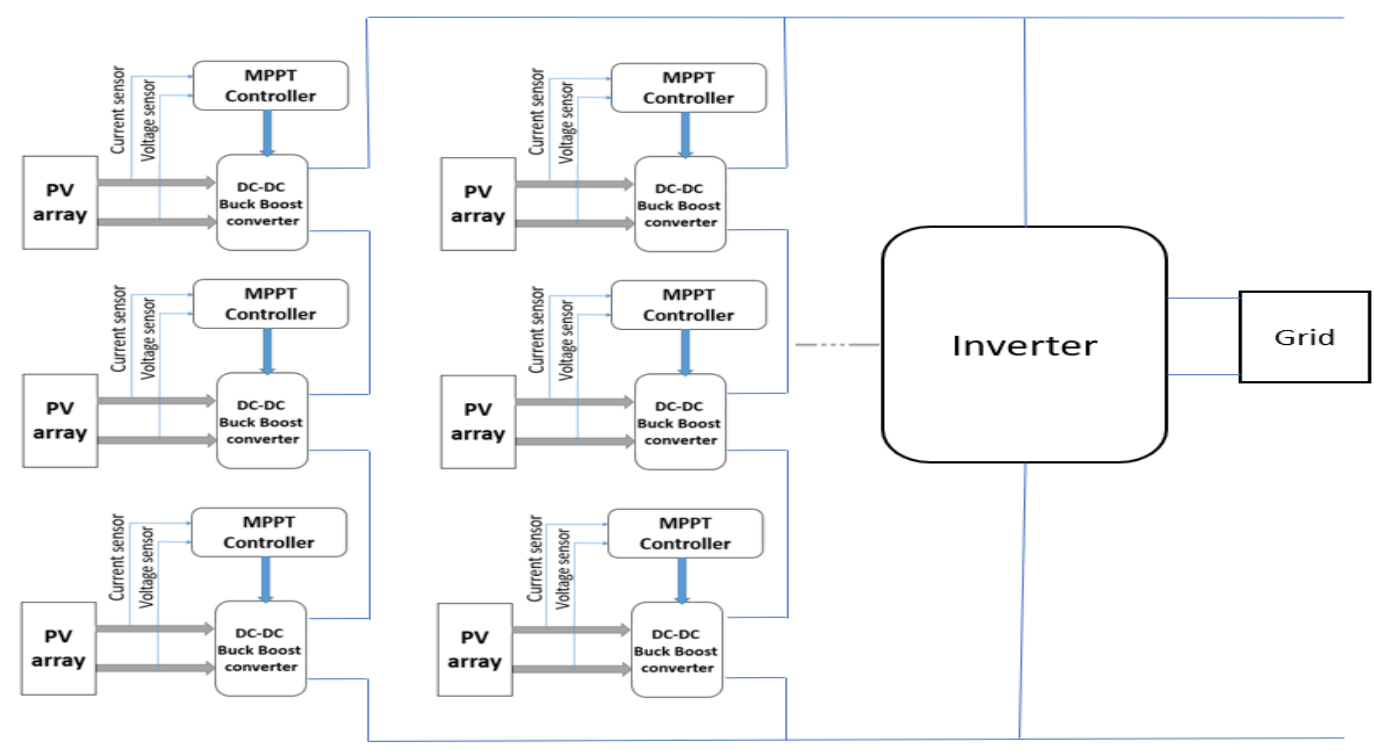

Figure 9. Grid-connected solar power system with distributed maximum power point tracking

\subsection{Intelligent Fuzzy/Bee controller design}

By applying this optimized function to a photovoltaic (PV) system, a novel approach is created, which, when compared to $\mathrm{P} \& \mathrm{O}$ and fuzzy methods, results in a significant increase in output power. Figure 10 shows 
the diagram of the proposed method. In fuzzy applications, fuzzy optimization is a critical topic. This paper proposes a fuzzy/bee control method, as can be seen in Figure 10, in order to overcome this troubling issue. In the proposed intelligent fuzzy/bee algorithm, the membership functions of the fuzzy method have been optimized with the honey bee algorithm, which causes a fast approach [47]. Based on Figure 10 and (7), (8), and (9), in order to assess the ABC population, the fitness function (objective function) is defined by mean square error (MSE), represented by (10).

$$
M S E / A B C=\frac{1}{N_{A B C}} \sum_{i=1}^{N}\left(Y_{\text {output }}(i)-Y_{\text {reference }}(i)\right)^{2}
$$

Where $Y_{\text {output }}(i)$ is the output in the i'th sample with a 25-rule base which covers five variables including negative big (NB), negative small (NS), ZE (zero), PS (positive small), and PB (positive big). In Figure 11, optimized membership functions have been shown. In this paper, we consider a 44kW solar PV system with the bee algorithm in which the number of bees is 200 , and the minimum of iteration is 300 .

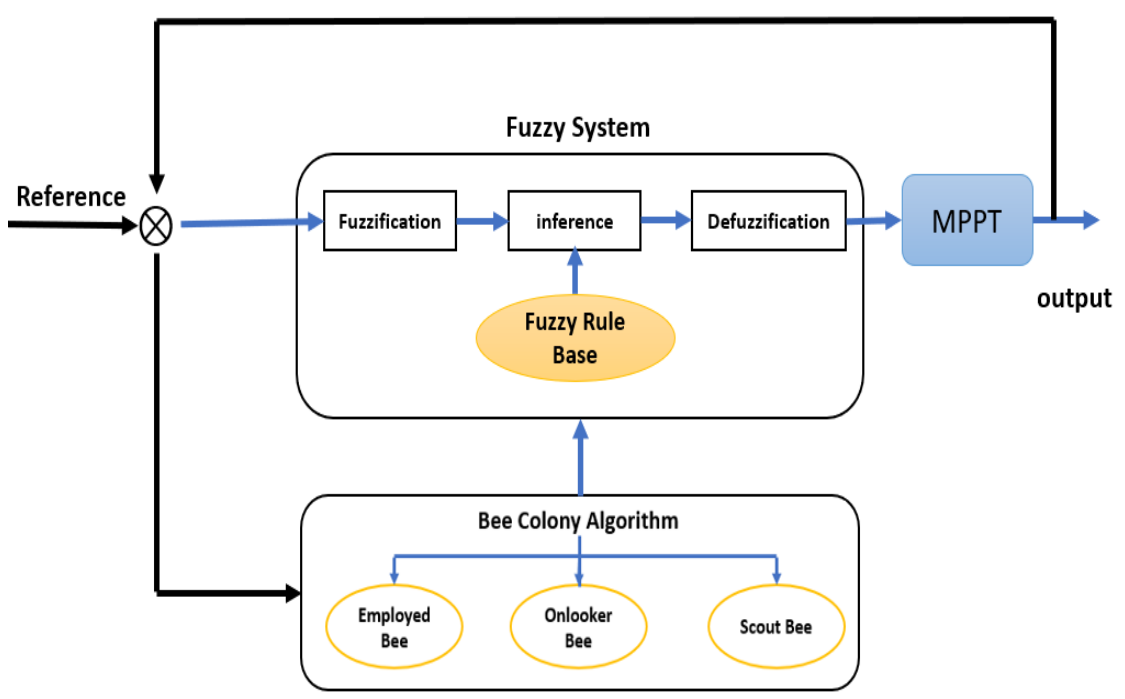

Figure 10. Diagram of Fuzzy/Bee Algorithm

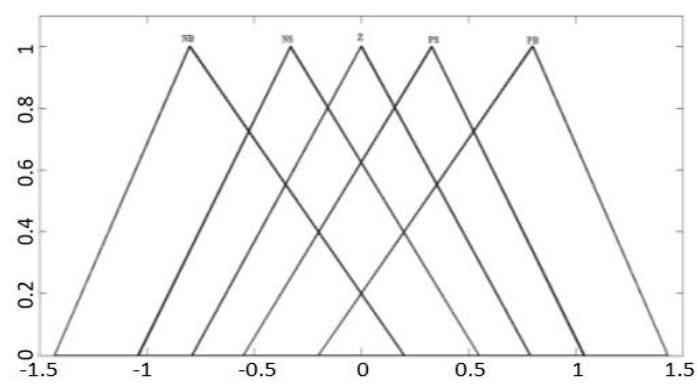

Figure 11. Fuzzy membership functions optimized with the Bee algorithm with five membership functions

\section{SIMULATION AND RESULTS}

On the basis of varied solar radiations and temperature levels, several aspects of Solar PV power modules are investigated. The PV system described in this study is made up of eight strings, each with 18 modules. Furthermore, the increment-decrement step size in the $\mathrm{P} \& \mathrm{O}$ algorithm is 0.035 . Also, the generated power is discussed using MATLAB Simulink. Figure 12 shows the output power of one module by simple MPPT using the P\&O method. As it is obvious based on Figure 13, the oscillation around the operating point in the $\mathrm{P} \& \mathrm{O}$ method is high, which causes some losses and lowers the efficiency by using this technique. In addition, Figure 14 displays the output power of a single module using the fuzzy technique. 

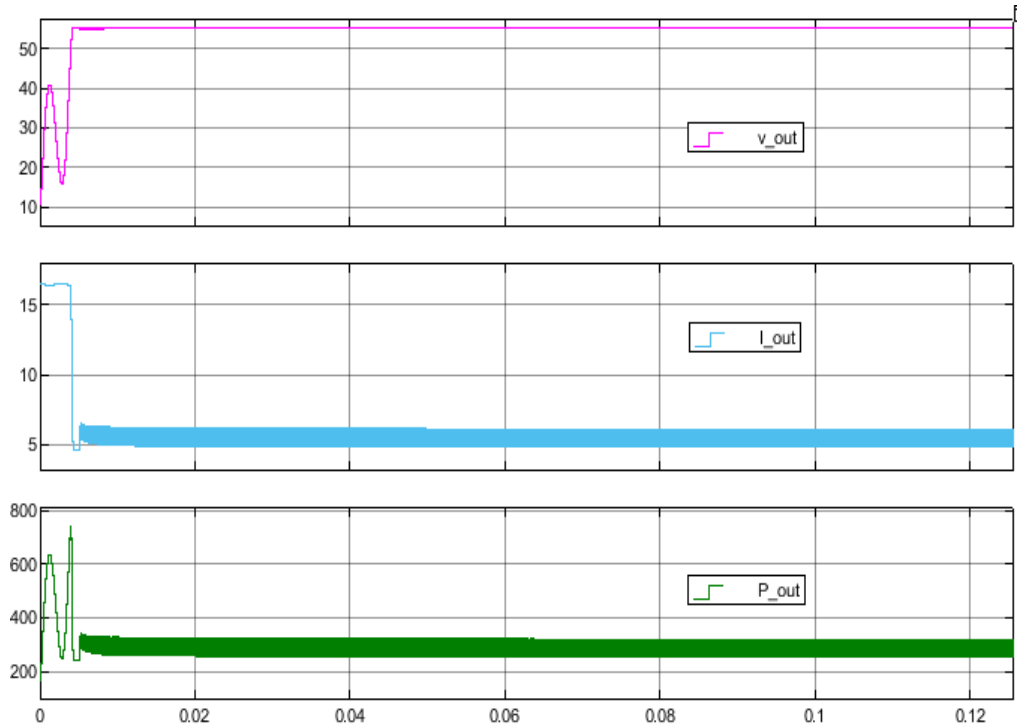

Figure 12. Power Extraction of one module by Individual MPPT with P\&O method

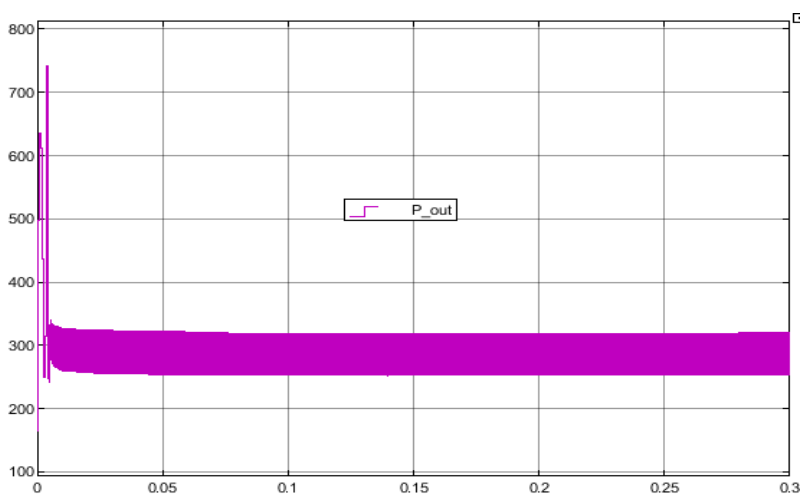

Figure 13. Oscillation around the operating point with the $\mathrm{P} \& \mathrm{O}$ method
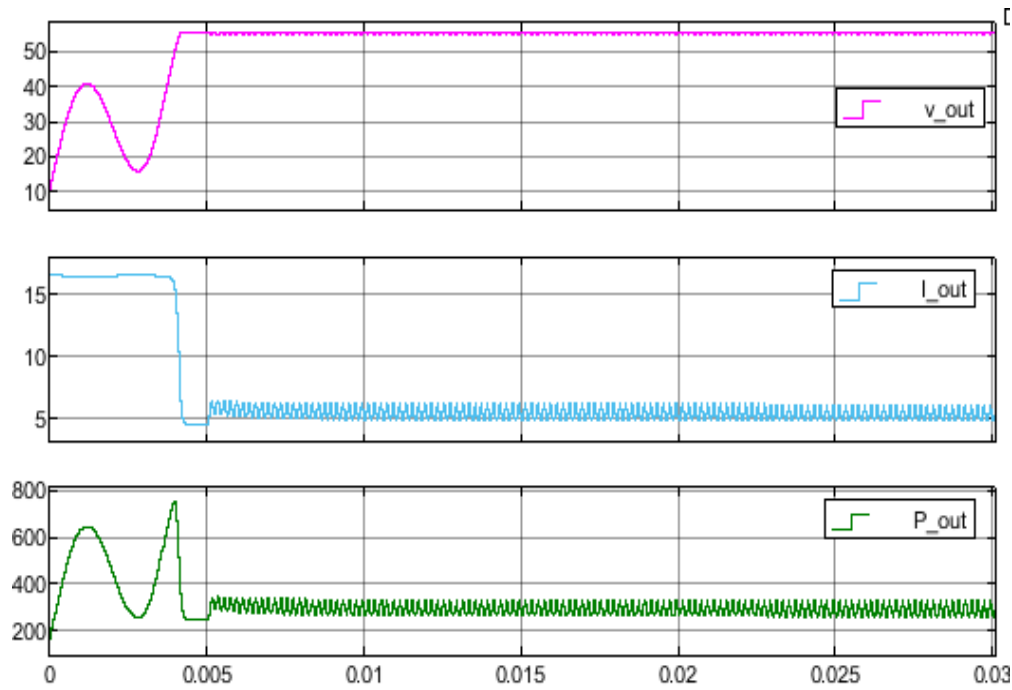

Figure 14. Power Extraction of one module by individual MPPT with Fuzzy method 
No need to mention that the fluctuation of power around the operating point in the fuzzy method is much less than the P\&O method, which can be seen in Figure 15. Finally, utilizing the fuzzy/bee approach, Figure 16 shows the output power of a single module. According to Figure 16, the generated power is a little higher than the previous techniques.

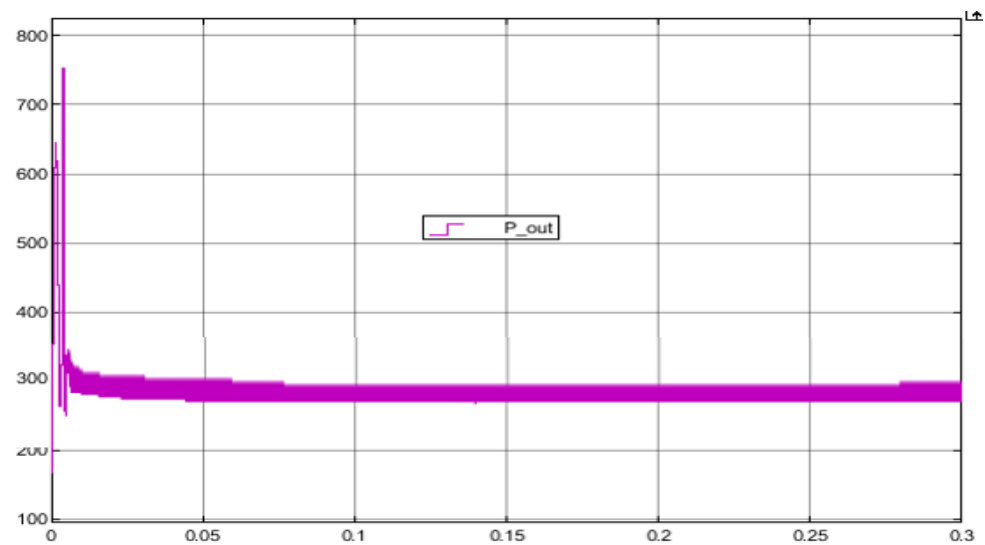

Figure 15. Lower oscillation around the operating point with Fuzzy method
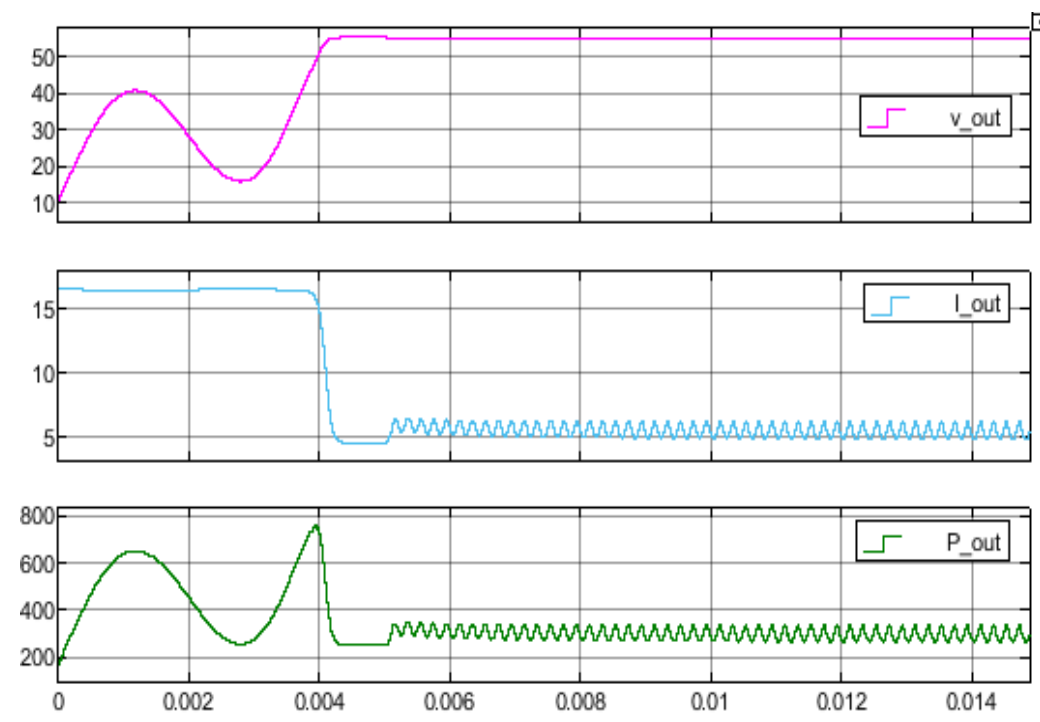

Figure 16. Power Extraction of one module by Individual MPPT with Fuzzy/Bee method

Therefore, in the fuzzy/bee method, fuzzy membership functions are optimized by the bee colony optimization algorithm so that the output power in the fuzzy/bee algorithm is more than the fuzzy method. Table 4 shows the extracted power of the presented solar system by three proposed methods.

Table 4. The generated power of one module with three different methods

\begin{tabular}{llll}
\hline & P\&O & FLC & FBA \\
\hline $\begin{array}{l}\text { Generated power of each module at solar } \\
\text { noon }\end{array}$ & $284.97 \mathrm{~W}$ & $292.11 \mathrm{~W}$ & $296.84 \mathrm{~W}$ \\
$\begin{array}{l}\text { Generated power of the whole PV system } \\
\text { at solar noon }\end{array}$ & $41035.64 \mathrm{~W}$ & $42063.84 \mathrm{~W}$ & $42744.96 \mathrm{~W}$ \\
\hline
\end{tabular}

The output power in the above three various methods varies, as shown in Table 4. At a steady-state, the highest output power for the entire system using the FBA is 296W. Due to changes in irradiance and 
ambient temperatures, the MPP of each Photovoltaic module may be unequal. The overall efficiency of a PV system can suffer if each module is not handled separately. As a result, DMPPT is critical in a large solar farm. To counteract the effect of mismatches, the PV module must be run at multiple voltage levels in order to maximize the use of each Photovoltaic module. To maximize the energy recovered from each string and achieve high photovoltaic system efficiency, the PV strings must be operated at various voltage levels.

\section{CONCLUSION}

The purpose of this paper is to use a combination technique to increase the quantity of energy harvested from solar PV arrays in a grid-connected system. Due to PSC, fluctuations in sun radiation, and temperature variations, the MPP of a solar cell fluctuates during the day. A DMPPT is demonstrated to improve the total efficiency of PV systems. Also, to overcome the problem with FLC and P\&O methods, the bee colony optimization technique is used to optimize fuzzy membership functions, increasing the speed of achieving the MPPs. Simulation results also demonstrate that just by using the proposed method, the output power will increase by around $4 \%$ which in huge solar farm is remarkable.

\section{REFERENCES}

[1] A. A. Lekvan, R. Habibifar, M. Moradi, M. Khoshjahan, S. Nojavan, and K. Jermsittiparsert, "Robust optimization of renewable-based multi-energy micro-grid integrated with flexible energy conversion and storage devices," Sustainable Cities and Society, vol. 64, p. 102532, 2021, doi: 10.1016/j.scs.2020.102532.

[2] H. Rezk, et al., "A novel statistical performance evaluation of most modern optimization-based global MPPT techniques for partially shaded PV system," Renewable and Sustainable Energy Reviews, vol. 115, p. 109372, 2019, doi: 10.1016/j.rser.2019.109372.

[3] D. P. Winston, S. Kumaravel, B. P. Kumar, and S. Devakirubakaran, "Performance improvement of solar PV array topologies during various partial shading conditions," Solar Energy, vol. 196, pp. 228-242, 2020, doi: 10.1016/j.solener.2019.12.007.

[4] C. Saiprakash, A. Mohapatra, B. Nayak, and S. R. Ghatak, "Analysis of partial shading effect on energy output of different solar PV array configurations," Materials Today: Proceedings, vol. 39, no. 5, pp. 1905-1909, 2021, doi: 10.1016/j.matpr.2020.08.307.

[5] M. Al-Dhaifallah, A. M. Nassef, H. Rezk, and K. S. Nisar, "Optimal parameter design of fractional order control based INC-MPPT for PV system,” Solar Energy, vol. 159, pp. 650-664, 2018, doi: 10.1016/j.solener.2017.11.040.

[6] P. Verma, R. Garg, and P. Mahajan, "Asymmetrical interval type-2 fuzzy logic control based MPPT tuning for PV system under partial shading condition," ISA transactions, vol. 100, pp. 251-263, 2020, doi: 10.1016/j.isatra.2020.01.009.

[7] A. Mohapatra, B. Nayak, P. Das, and K. B. Mohanty, "A review on MPPT techniques of PV system under partial shading condition," Renewable and Sustainable Energy Reviews, vol. 80, pp. 854-867, 2017, doi: 10.1016/j.rser.2017.05.083.

[8] R. B. Bollipo, S. Mikkili and P. K. Bonthagorla, "Hybrid, optimal, intelligent and classical PV MPPT techniques: A review," in CSEE Journal of Power and Energy Systems, vol. 7, no. 1, pp. 9-33, Jan. 2021, doi: 10.17775/CSEEJPES.2019.02720.

[9] A. Ali et al., "Investigation of MPPT Techniques Under Uniform and Non-Uniform Solar Irradiation Condition-A Retrospection," in IEEE Access, vol. 8, pp. 127368-127392, 2020, doi: 10.1109/ACCESS.2020.3007710.

[10] H. S. Sahu, S. K. Nayak and S. Mishra, "Maximizing the Power Generation of a Partially Shaded PV Array," in IEEE Journal of Emerging and Selected Topics in Power Electronics, vol. 4, no. 2, pp. 626-637, June 2016, doi: 10.1109/JESTPE.2015.2498282.

[11] S. Motahhir et al., "Optimal Energy Harvesting From a Multistrings PV Generator Based on Artificial Bee Colony Algorithm," in IEEE Systems Journal, vol. 15, no. 3, pp. 4137-4144, Sept. 2021, doi: 10.1109/JSYST.2020.2997744.

[12] A. S. Benyoucef, A. Chouder, K. Kara, S. Silvestre, and O. A. Sahed, "Artificial bee colony based algorithm for maximum power point tracking (MPPT) for PV systems operating under partial shaded conditions," Applied Soft Computing,vol. 32, pp. 38-48, 2015, doi: 10.1016/j.asoc.2015.03.047.

[13] C. Chen, K. Chen and Y. Chen, "Modeling and Controller Design of an Autonomous PV Module for DMPPT PV Systems," in IEEE Transactions on Power Electronics, vol. 29, no. 9, pp. 4723-4732, Sept. 2014, doi: 10.1109/TPEL.2013.2287752.

[14] R. Fraranda and S. Leva, "Energy comparison of MPPT techniques for PV Systems," WSEAS transactions on power systems, vol 3, no. 6, pp. 446-455, 2008.

[15] C. H. H. Basha and C. Rani, "Performance analysis of MPPT Techniques for dynamic irradiation condition of Solar PV," International Journal of Fuzzy Systems, vol. 22, no. 8, pp. 2577-2598, 2020, doi: 10.1007/s40815-020-00974$\mathrm{y}$.

[16] A. Balal and M. Mursehed, "Implementation and comparison of Perturb and Observe, and Fuzzy Logic Control on Maximum Power Point Tracking (MPPT) for a Small Satellite," Journal of Soft Computing and Decision Support Systems, vol. 8, no. 2, pp.14-18, 2021. 
[17] M. N. Dehedkar and S. Vitthalrao Murkute, "Optimization of PV System using Distributed MPPT Control," 2018 International Conference on System Modeling \& Advancement in Research Trends (SMART), 2018, pp. 216-220, doi: 10.1109/SYSMART.2018.8746931.

[18] A. Yousefiankalareh, A. Najari and M. Hosseynzadeh, "Tree-based Routing Protocol in Wireless Sensor Networks using Optimization Algorithm Batch Particles with a Mobile Sink," 2020 IEEE 17th International Conference on Smart Communities: Improving Quality of Life Using ICT, IoT and AI (HONET), 2020, pp. 1-5, doi: 10.1109/HONET50430.2020.9322844.

[19] S. P. Sukhatme and J. K. Nayak, Solar energy, McGraw-Hill Education, 2017.

[20] C. Huang, M. Hwang, H. Chen and P. Kuo, "PV System Power Model Application in Smart Cities," 2019 IEEE 2nd International Conference on Knowledge Innovation and Invention (ICKII), 2019, pp. 31-32, doi: 10.1109/ICKII46306.2019.9042691.

[21] G L. Gao, R. A. Dougal, S. Liu and A. P. Iotova, "Parallel-Connected Solar PV System to Address Partial and Rapidly Fluctuating Shadow Conditions," in IEEE Transactions on Industrial Electronics, vol. 56, no. 5, pp. 1548-1556, May 2009, doi: 10.1109/TIE.2008.2011296.

[22] A. Balal, S. Rhukh, and S. Balali, "Designing a Dual Active Transformer DC-DC Forward Converter for DC MicroGrid Applications Using LTSPICE," International Journal of Applied Engineering Research, vol. 16, no. 4, pp. 327 331,2021

[23] S. D. Dehnavi and E. Shayani, "Compensation of Voltage disturbances in hybrid AC/DC Microgrids using series converter," Ciência e Natura, vol. 37, no. (6-2), pp. 349-356, 2015, doi: 10.5902/2179460X20794.

[24] P. Azer and A. Emadi, "Generalized State Space Average Model for Multi-Phase Interleaved Buck, Boost and BuckBoost DC-DC Converters: Transient, Steady-State and Switching Dynamics,” in IEEE Access, vol. 8, pp. 7773577745, 2020, doi: 10.1109/ACCESS.2020.2987277.

[25] S. D. Dehnavi, M. Shahparasti, M. Simab, and S. M. B. Mortazavi, "Employing interface compensators to enhance the power quality in hybrid AC/DC microgrids," Ciência e Natura, vol. 37, no. (6-2), pp. 357-363, 2015, doi: 10.5902/2179460X20796.

[26] M. Gheisarnejad, H. Farsizadeh, M. -R. Tavana and M. H. Khooban, "A Novel Deep Learning Controller for DCDC Buck-Boost Converters in Wireless Power Transfer Feeding CPLs," in IEEE Transactions on Industrial Electronics, vol. 68, no. 7, pp. 6379-6384, July 2021, doi: 10.1109/TIE.2020.2994866.

[27] K. Osmani, A. Haddad, T. Lemenand, B. Casranier, and M. Ramadan, "An investigation on maximum power extraction algorithms from PV systems with corresponding DC-DC converters," Energy, vol. 224, p. 120092, 2021, doi: 10.1016/j.energy.2021.120092.

[28] P. Manoharan et al., "Improved Perturb and Observation Maximum Power Point Tracking Technique for Solar Photovoltaic Power Generation Systems," in IEEE Systems Journal, vol. 15, no. 2, pp. 3024-3035, June 2021, doi: 10.1109/JSYST.2020.3003255.

[29] R. Ahmad, A. F. Murtaza, and H. A. Sher, "Power tracking techniques for efficient operation of photovoltaic array in solar applications-A review," Renewable and Sustainable Energy Reviews, vol. 101, pp. 82-102, 2019, doi: 10.1016/j.rser.2018.10.015

[30] F N. Femia, G. Petrone, G. Spagnuolo and M. Vitelli, "A Technique for Improving P\&O MPPT Performances of Double-Stage Grid-Connected Photovoltaic Systems," in IEEE Transactions on Industrial Electronics, vol. 56, no. 11, pp. 4473-4482, Nov. 2009, doi: 10.1109/TIE.2009.2029589.

[31] A. K. Abdelsalam, A. M. Massoud, S. Ahmed and P. N. Enjeti, "High-Performance Adaptive Perturb and Observe MPPT Technique for Photovoltaic-Based Microgrids," in IEEE Transactions on Power Electronics, vol. 26, no. 4, pp. 1010-1021, April 2011, doi: 10.1109/TPEL.2011.2106221.

[32] B. Moaveni, F. R. Fathabadi, and A. Molavi, "Fuzzy control system design for wheel slip prevention and tracking of desired speed profile in electric trains," Asian Journal of Control, p. 2472, 2020, doi: 10.1002/asjc.2472.

[33] U. Yilmaz, A. Kircay, and S. Borekci, "PV system fuzzy logic MPPT method and PI control as a charge controller, “Renewable and Sustainable Energy Reviews, vol. 81, no. 1, pp. 994-1001, 2018, doi: 10.1016/j.rser.2017.08.048.

[34] F. R. Fathabadi, J. L. Grantner, S. A. Shebrain and I. Abdel-Qader, "Multi-Class Detection of Laparoscopic Instruments for the Intelligent Box-Trainer System Using Faster R-CNN Architecture," 2021 IEEE 19th World Symposium on Applied Machine Intelligence and Informatics (SAMI), 2021, pp. 000149-000154, doi: 10.1109/SAMI50585.2021.9378617.

[35] H. Rezk, M. Aly, M. Al-Dhaifallah and M. Shoyama, "Design and Hardware Implementation of New Adaptive Fuzzy Logic-Based MPPT Control Method for Photovoltaic Applications," in IEEE Access, vol. 7, pp. 106427-106438, 2019, doi: 10.1109/ACCESS.2019.2932694.

[36] A. Al Nabulsi and R. Dhaouadi, "Efficiency Optimization of a DSP-Based Standalone PV System Using Fuzzy Logic and Dual-MPPT Control," in IEEE Transactions on Industrial Informatics, vol. 8, no. 3, pp. 573-584, Aug. 2012, doi: 10.1109/TII.2012.2192282.

[37] A. Adami, M. Morovati, and H. Ahani, "Design A Gain Scheduled Fuzzy Controller For Distributed Parabolic Solar Collectors," Annals of the Faculty of Engineering Hunedoara-International Journal of Engineering, vol. 1, no. 1, pp. 121-126, 2021.

[38] R. S. Taremi, P. K. Shahri, and A. Y. Kalareh, "Design a tracking control law for the nonlinear continuous time fuzzy polynomial systems," Journal of Soft Computing and Decision Support Systems, vol. 6, no. 6, pp. 21-27, 2019.

[39] B. Bendid, F. Krim, H. Belmili, M. F. Almi, and S. Boulouma, "Advanced Fuzzy MPPT Controller for a stand-alone PV system," Energy Procedia, vol. 50, pp. 383-392, 2014, doi: 10.1016/j.egypro.2014.06.046.

[40] L. Xingshou, W. Huiqing, H. Yihua, and J. Lin, "A novel beta parameter based fuzzy-logic controller for photovoltaic MPPT application," Renewable energy, vol. 130, pp. 416-427, 2019, doi: 10.1016/j.renene.2018.06.071. 
[41] M. N> Ali, K. Mahmoud, M. Lehtonen, and M. M. F. Darwish, "Promising MPPT Methods Combining Metaheuristic, Fuzzy-Logic and ANN Techniques for Grid-Connected Photovoltaic," Sensors, vol. 21, no. 4, p. 1244, 2021, doi: $10.3390 / \mathrm{s} 21041244$.

[42] A. S> Oshaba and S. M. Abd Elzim, "PI controller design using ABC algorithm for MPPT of PV system supplying DC motor pump load," Neural Computing and Applications, vol. 28, no. 2, pp. 353-364, 2017, doi: 10.1007/s00521015-2067-9.

[43] R. B. Bollipo, S. Mikkili, and P. K. Bonthagorla, "Critical review on PV MPPT techniques: classical, intelligent and optimisation," IET Renewable Power Generation, vol. 14, no.9, pp. 1433-1452, 2020, doi: 10.1049/ietrpg.2019.1163.

[44] S. Motahhir, A. El Hammoumi, and A. El Ghzizal, "The most used MPPT algorithms: Review and the suitable lowcost embedded board for each algorithm," Journal of cleaner production, vol. 246, p. 118983, 2020, doi: 10.1016/j.jclepro.2019.118983.

[45] S. Motahhie, and E. M. Ali, "Advanced Technologies for Solar Photovoltaics Energy Systems," Springer Nature, 2021.

[46] J. Jiang, T. Zhang and D. Chen, “Analysis, Design, and Implementation of a Differential Power Processing DMPPT With Multiple Buck-Boost Choppers for Photovoltaic Module," in IEEE Transactions on Power Electronics, vol. 36, no. 9, pp. 10214-10223, Sept. 2021, doi: 10.1109/TPEL.2021.3063230.

[47] S. Padmanaban, N. Priyadarshi, M. Sagar Bhaskar, J. B. Holm-Nielsen, V. K. Ramachandaramurthy and E. Hossain, "A Hybrid ANFIS-ABC Based MPPT Controller for PV System With Anti-Islanding Grid Protection: Experimental Realization," in IEEE Access, vol. 7, pp. 103377-103389, 2019, doi: 10.1109/ACCESS.2019.2931547. 